\title{
INNOVATIVE PROCESSING ROUTES IN MANUFACTURING OF METAL MATRIX COMPOSITE MATERIALS
}

\author{
Jovana Ružić ${ }^{1, *}$, Marko Simićl, Nikolay Stoimenov ${ }^{2}$, Dušan Božićc ${ }^{1}$, \\ Jelena Stašićl \\ ${ }^{1}$ Department of Materials, "Vinča" Institute of Nuclear Sciences - National Institute of \\ the Republic of Serbia, University of Belgrade, PO Box 522, 11001 Belgrade, Serbia \\ ${ }^{2}$ Institute of Information and Communication Technologies, Bulgarian Academy of \\ Sciences, Sofia, Bulgaria
}

Received 23.03.2021

Accepted 29.03.2021

\begin{abstract}
Metal matrix composites (MMCs) belong to a group of modern materials owing to their excellent technological, mechanical, and physical properties such as excellent wear and corrosion resistance, high electrical and thermal conductivity, improved strength and hardness. Final properties of MMCs are affected equally by all steps of its manufacturing process. It is shown that by using adequate process parameters to obtain starting materials (reaching the specific size, shape, and reactivity) the control of volume fraction and distribution of reinforcements within the matrix can be achieved. For this purpose, mechanical alloying has been appointed as a good approach. MMCs can be produced using powder metallurgy, ingot metallurgy, and additive manufacturing techniques. Combining high-energy ball milling with these techniques enables the design of an innovative processing route for MMCs manufacturing. Mechanochemical process (achieved using high-energy ball milling) was employed in three manufacturing procedures: hot pressing, compocasting, and laser melting/sintering for obtaining of the suitable powder. These production routes for MMCs manufacturing were the subject of this work. The aim of MMCs design is to establish an optimal combination of production techniques merged into the cost-effective fabrication route for obtaining MMCs with required properties.
\end{abstract}

Keywords: metal matrix composites; mechanical alloying; powder metallurgy; compocasting; laser melting/sintering. 


\section{Introduction}

People were always aware, even from our early beginnings, of the fact that mixing different material systems can provide them with an abundance of alterations and a variety of operating properties [1-6]. Materials composed of two components, matrix and reinforcements, different by their physical and mechanical properties are named composite materials. Broad classification of composite materials is done based on the material used as continuous phase i.e. matrix: metal matrix composites (MMCs), ceramic matrix composites (CMCs), polymer matrix composites (PMCs), and carbon matrix composites (x/CMCs, where $\mathrm{x}$ is an abbreviation of the material used as reinforcement). Additionally, composites are divided into subgroups according to the size of reinforcements as macro-, micro-, and nanocomposites. In recent years, nanocomposites are in the focus of many studies due to their excellent properties provided by the usage of nanotubes and nanoparticles as reinforcements. From the perspective of the reinforcement geometry, composites are distinguished as particle-reinforced composites, fiberreinforced composites, and short/chopped fiber -reinforced composites [4].

First examples of composite materials with metal matrix utilization can be found in ancient civilizations and taking a trip through the centuries, one could encounter a plethora of cases where these systems have been used. The first known application of metal matrix composites in the manufacturing of copper awls dates all the way back to 7000 BC (found at Cayonu, a Neolithic settlement in southeastern Turkey) [7]. It is safe to claim that, from that point on, the world would never be the same. Through time, as people progressed so did the MMCs improve. Cases of applications kept on appearing in all parts of the world such as an iron plate (consisted of numerous laminates where each layer differs from the other in microstructural properties and amount of inclusions) excavated in the southern side of the Great Pyramid at Gizeh, Egypt, dating back to 2750 BC [8]; more then 1000 year old samurai sword (Japan) contains of two different layers (middle brittle layer made of folded steel while for edge layers the softer steel are used) [9]; ancient Indonesian Kris knife consists of many different layers containing various content of iron, steel and iron-nickel alloy [10].

MMCs have progressed because of their vast scope of desirable properties primarily excellent mechanical and physical properties. The main intent behind their development relies on the ability to associate appealing properties of metals (toughness and durability) with the second phase (stiffness and high strength). In comparison with the unreinforced alloys, it becomes evident why MMCs take primacy in structural applications. They are distinguished by their improved specific strength and stiffness, and there are multiple ways to exploit such boosts of the specific properties. The predominant approach concerns weight savings and/or improved fatigue resistance. If prime advantages shown by MMCs were to be showcased, lower density, increased hightemperature performance limits, increased specific strength and stiffness, as well as improved wear-abrasion resistance, cannot be overlooked. Naturally, these properties hinge on the properties of its constituents. When opting for a specific matrix, the focal point of the selection has to be on the nature of the reinforcing phase. The $\mathrm{SiC}$ and $\mathrm{Al}_{2} \mathrm{O}_{3}$ particles are the most used as reinforcements of the metal matrix, although, in recent years, there is extensive use of reinforcements as $\mathrm{TiO}_{2}, \mathrm{TiB}_{2}, \mathrm{TiC}, \mathrm{ZrO}_{2}, \mathrm{ZrB}_{2}$, nanotubes, biomaterials, carbon fibers, etc. Generally, MMCs contain one type of reinforcing particles, but recently a new group of MMCs was established, named hybrid MMC, containing more than one sort of reinforcements was reported [4-6,11]. Besides the nature 
and geometry of reinforcements, composite materials can be classified according to the reinforcements' forming method. Therefore, there are in situ composites where reinforcements are formed in the matrix during manufacturing, and ex situ composites where reinforcements are externally formed and subsequently added to the matrix. The qualitative selection of materials used for reinforcements in MMCs depends on a couple of factors. It is essential for the selected materials to be evaluated individually, as well as on their interactivity with each other. The problem arises regarding the interaction between reinforcement material and matrix material as, on numerous occasions, some of the materials are unable to be put together. Hence, microstructural properties strongly depend on the nature of interfacial bonding between reinforcing particles and metal matrix, as well as the added amount of reinforcements. Another issue is reaching the optimal microstructure where reinforcements will be uniformly distributed within the metal matrix. One of the methods for obtaining uniform distribution within the metal matrix is mechanical alloying as a technique for preparing a starting material with desirable properties. Investigation of the influence of reinforcements' properties on final properties of MMCs is performed by both researchers and engineers. Lately, computational researchers have shown a great interest in analyzing the influence of milling parameters on microstructure employing various computational models and simulations. One of the programs which can be used for control of microstructure by ball milling process is a software based on discrete element modeling (DEM) called EDEM $[12,13]$. The software is suitable for simulation and analyses of various materials like ores, soils, powders, milling bodies, and other bulk materials. It provides information on how the observed material will interact with other materials, investigates the trajectories of the particles during milling, and tracks responses of the overall process to the parameters change. The utilization of models and simulations of mechanical alloying and milling techniques contributes to a better understanding of the behavior of a wide variety of MMCs and facilitates their engineering applications. Regarding the type of metals used as a matrix in MMCs materials, five distinctive categories of these systems exist, with them being aluminum matrix composites, copper matrix composites, magnesium matrix composites, titanium matrix composites, and super alloy matrix composites [4-6]. The design of MMCs and the selection of their production process strongly depend on the application of MMCs and required properties. MMCs can be produced using conventional techniques such as powder metallurgy and ingot metallurgy, or contemporary techniques like additive manufacturing. The present paper aims to highlight the advantages of combining high-energy ball milling technique with powder metallurgy (hot pressing), ingot metallurgy (compocasting), and additive manufacturing techniques (laser melting/sintering) with an aim to provide a new production routine of MMCs manufacturing. 


\section{High-energy ball mill}

Powder materials have been used as starting materials in many production processes and have wide industrial applications in nanotechnology, mining, automotive, space, pharmaceutical and food industries. Owing to their broad applications, particle size distribution has been the subject of many studies. Changing the particle size and shape can be done by applying the methods such as breaking, crushing, grinding, cutting, etc. The technique for the particle size decreasing is known as milling since this process is carried out using mills. Particle size reduction is achieved by particle fracture applying different types of stress (compressive, shear, and impact forces) using the milling media (grinding bodies). The most commonly used grinding bodies are: balls, rods (for coarse milling), cylpebs (for pulverization) [14]. Inside the mill, the force can be applied as: pressure on material caused by milling media, the collision between particles and milling media, the friction of particles or through the milling environment. Applied force generates defects in material structure which promote crack propagation and lead to material breakage.

According to energy consumption, the milling devices can be divided into three categories: low-energy, medium-energy, and high-energy mills [15]. The low-energy mills are used for particle deagglomeration of for obtaining the particles with smooth edges. On the other hand, high-energy mills provide much higher kinetic energy compared to low-energy mills, and their application is in cases when the direct phase transformation is required or when particle size reduction should be achieved in a very short time. During the milling process, grinding media (balls) and particles exhibit very complex behavior considering their independent and mutual interactions. Parameters which affect the milling process are ball to powder ratio, rotation speed, milling duration, temperature, atmosphere (inert or air), type of process (dry or wet). The milling media's movement induces the balls' velocity, the number of collisions between balls themselves, and between balls and particles, as well as the balls' impact intensity. Therefore, milling media's size and speed have a significant influence on milling energy, which directly dictates the size, shape, and activation of output powder materials. Milling media motion inside the mill depends on mill type, rotation speed, and powder amount. Schematic view of various ball mill classifications, which depend on the operating parameters and construction, is displayed in Fig.1. 


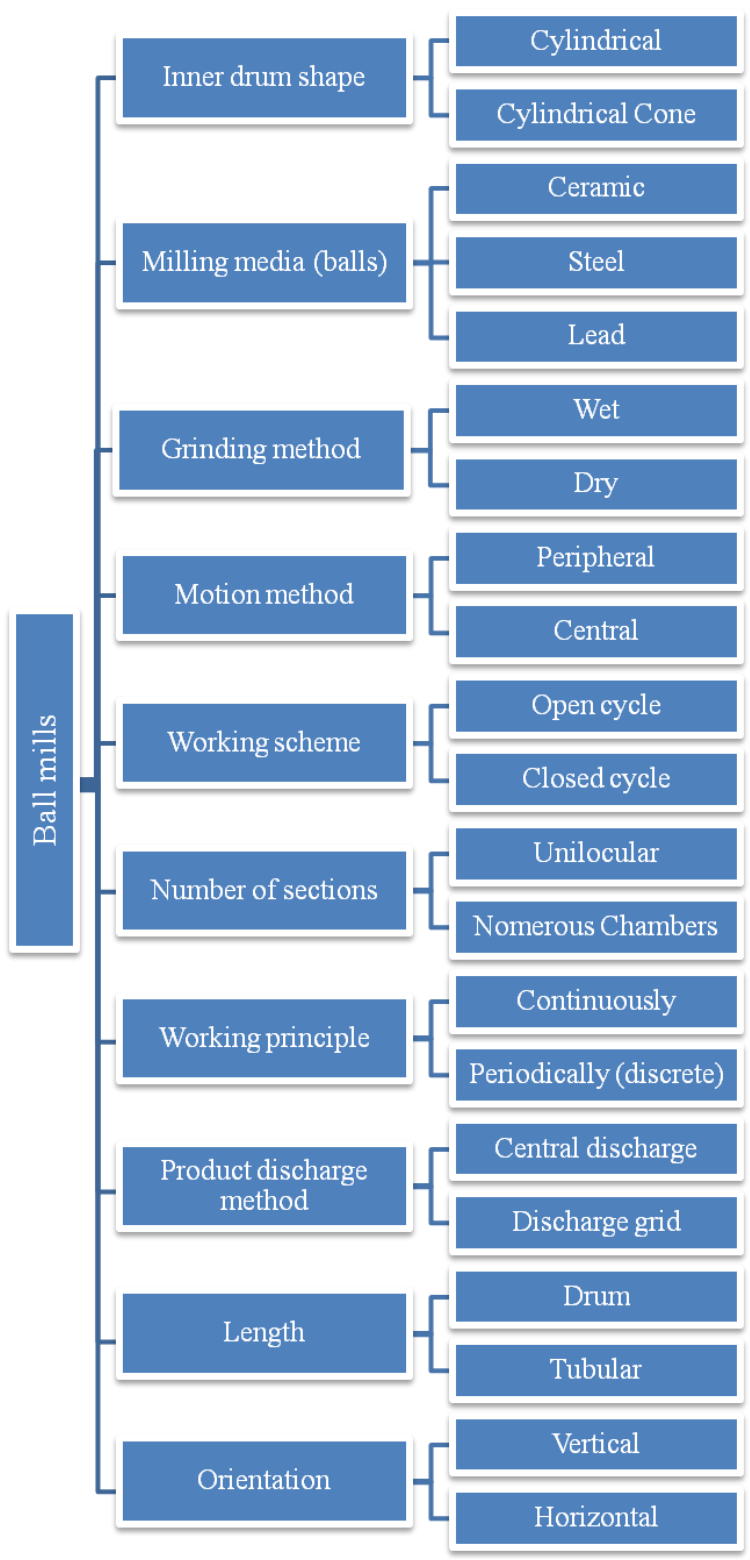

Fig.1. Classifications of ball mills according to their construction and operating parameters.

\section{Mechanical alloying}

The high-energy ball milling technique used for mechanically importing alloying elements in a metal matrix, with the aim to produce powder materials with controlled microstructure, is called mechanical alloying. Mechanical alloying (MA) can be applied in manufacturing of various materials such as MMCs, biomaterials, light metals, 
superconductors, superalloys, intermetallics, nanomaterials, amorphous materials, etc. The most used mill for mechanical alloying process is the attritor (Fig. 2). Controlled microstructure is achieved applying adequately optimized MA parameters: the rotation speed of mixer, balls' velocity (input energy), ball to powder ratio, the amount and properties of starting powders, the content of alloying elements, temperature (lower temperatures promote the formation of amorphous or nanocrystalline phases, while higher temperatures stimulate the formation of intermetallics, mechanically activated reinforcements, etc.) and atmosphere inside the mill [16-20].

Deformation, fracture, and cold welding mechanisms are present during the MA process. At different stage of MA process different mechanism is dominant. At the beginning of MA, deformation is the dominant process. With increasing the time of MA and number of collisions balls-powder, high strain rate deformation occurs and causes particles' fractures. On the other hand, an increased number of balls-powder collisions leads to a cold welding process. Reaching the proper balance between fracturing and cold welding is required for the successful formation of controlled microstructure. At this stage, the particles possess a flat shape, and microstructural refinement occurs. The main advantages of MA technique compared to other ball milling processes are shorter process duration and better control of alloying elements distribution within a metal matrix.

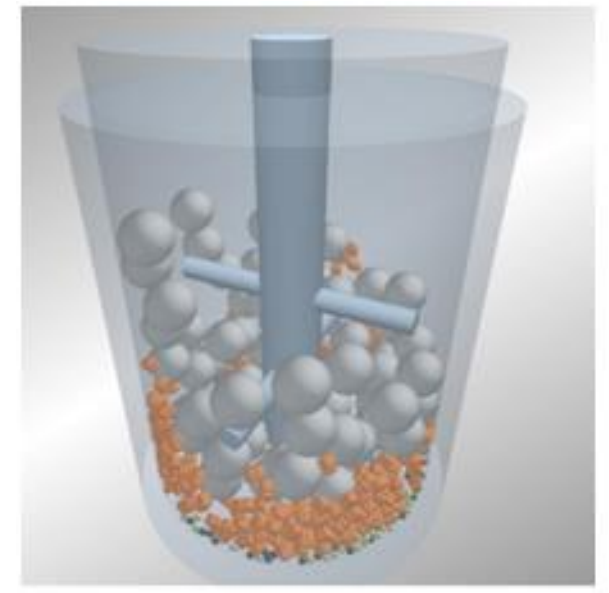

a)

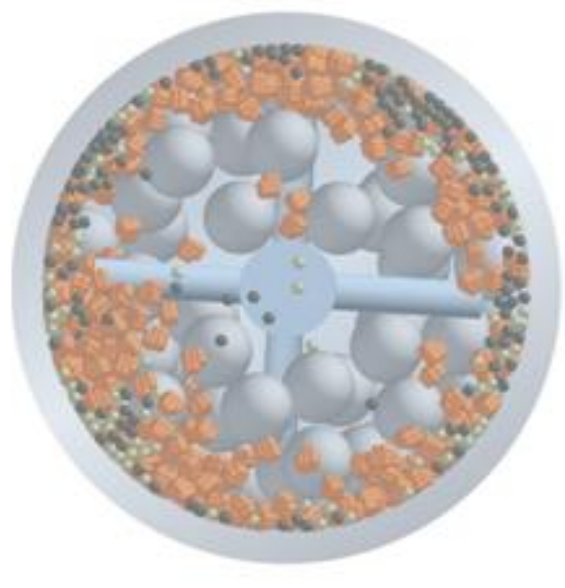

b)

Fig. 2. The simulation of mechanical alloying process in attritor obtained by EDEM software a) vertical view, b) bottom view of the attritor [12].

\section{MMCs production techniques}

Composite materials with the metal matrix are generally manufactured either by powder metallurgy or ingot metallurgy techniques. In the last years, there is an increased interest in the synthesis of this group of materials by selective laser melting/sintering. 


\section{Powder metallurgy}

Powder metallurgy (PM) uses matrix in powder form and it consists of two-steps process: (i.) preparation of starting material (mixing, milling, and mechanical alloying) and, (ii.) densification of the prepared powder mixture (cold or hot pressing, sintering, forging, etc.). Homogenization of starting materials combined with mechanical alloying provides controlled and desirable distribution of reinforcements within the matrix during densification process. Powder metallurgy is mainly classified into two types, the pressureless sintering process and the pressure-assisted sintering (hot-pressing) process. In the pressureless sintering process, mechanically alloyed powders are consolidated using cold press at room temperature and sintered in a furnace. One of the advantages of the pressureless process is that the density variation can be avoided in the final product. Pressure-assisted sintering process involves simultaneous application of pressure and heat, which can be adopted to produce fully dense composites. Thereby enhancement in the mechanical, wear, thermal and electrical properties of the materials can be achieved. The synthesis of copper-based composites reinforced with nano- and micro-zirconium diboride $\left(\mathrm{ZrB}_{2}\right)$ particles is used as an illustrative example of the PM technique [21,22]. Combining mechanical alloying (Fig. 3a) with hot pressing process (Fig. 3b) can contribute to the development of a potential process for production of advanced composite materials such as metal borides in the copper matrix. This production route aims to provide the mechanically activated particles ( $\mathrm{Zr}$ and $\mathrm{B}$ ) which will in situ form $\mathrm{ZrB}_{2}$ particles during the hot pressing process. Adding $\mathrm{ZrB}_{2}$ as a hardening phase to the copper matrix significantly improves mechanical properties, wear and spark resistance, as well as maintains high electrical and thermal conductivity of $\mathrm{Cu}$ matrix composites.

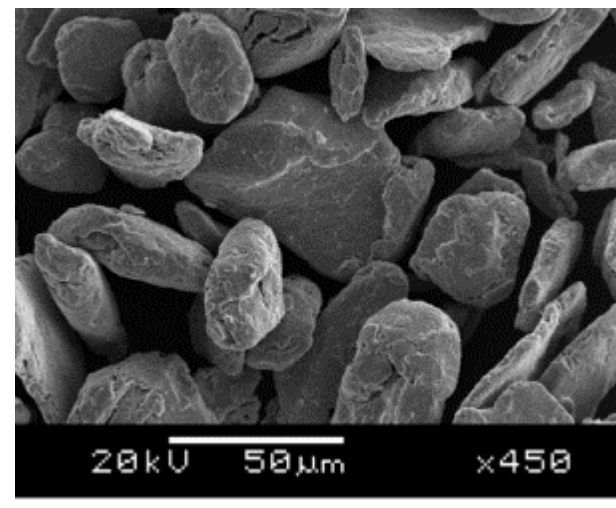

a)

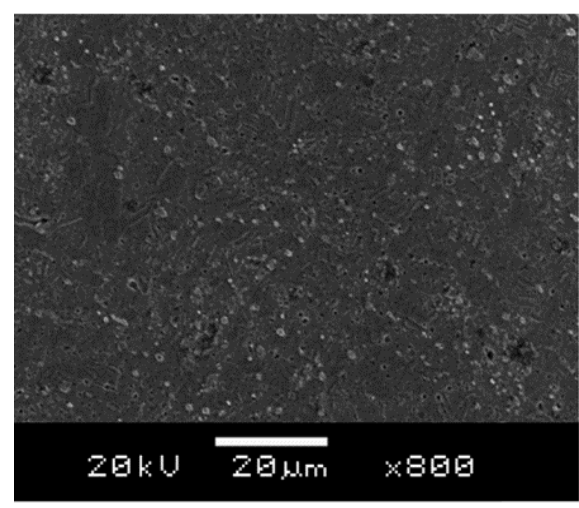

b)

Fig. 3. SEM: a) the shape and size of mechanically alloyed $\mathrm{Cu}$-Zr-B powders for $30 \mathrm{~h}$; b) microstructure of $\mathrm{Cu}-\mathrm{ZrB} \mathrm{B}_{2}$ compacts made by hot pressed process [21].

\section{Ingot metallurgy}

Ingot metallurgy uses matrix in a liquid form where a metal matrix is brought above its liquidus temperature through casting techniques (hot forming, liquid pressure forming, squeeze casting, etc.). Modified casting techniques that use metals in a semisolid state, known as compocasting, rheocasting, and thixocasting, are being actively in use [23]. Even though powder metallurgy is extensively exploited for MMCs 
manufacturing [24-27], modified casting processing techniques can be employed as well [28-33]. Compared to powder metallurgy, the main disadvantage of casting process is the lack of control over distribution of imported reinforcements within the metal matrix. This issue can be overcome using the high-energy ball milling technique as pre-process step where reinforcements will be properly distributed on carriers. Recent studies [29,30] report an innovative processing route for producing ZA-27 alloy-based nanocomposites. This newly developed MMCs manufacturing routine combines high-energy ball milling and compocasting technique in order to incorporate nano-scaled reinforcements into the semi-molten matrix, where scarp of matrix material (ZA-27 alloy) is used as carrier material (Fig.3). It was shown that during the high-energy ball milling nano-sized ceramic reinforcements have interacted with ZA-27 alloy matrix scrap which resulted in forming of composite microparticles. Subsequently, formed composite microparticles are inserted in the semi-molten matrix. This innovative processing route resulted in a good distribution of ceramic nanoparticles in the ZA-27 alloy matrix. A good distribution and presence of ceramic nanoparticles improved overall strengthening, increased the hardness and wear resistance.

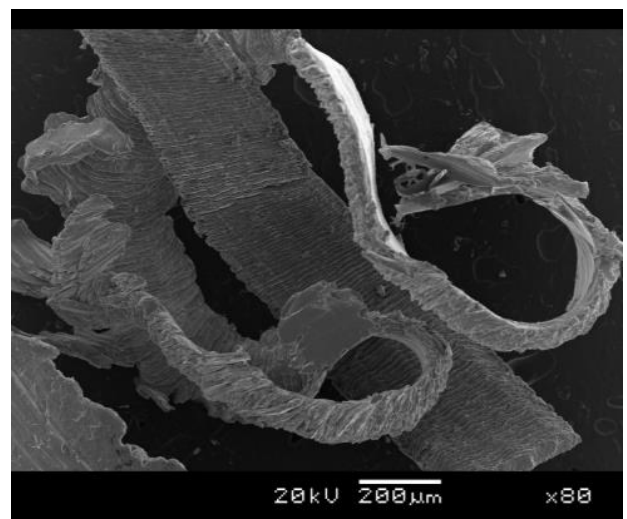

a)

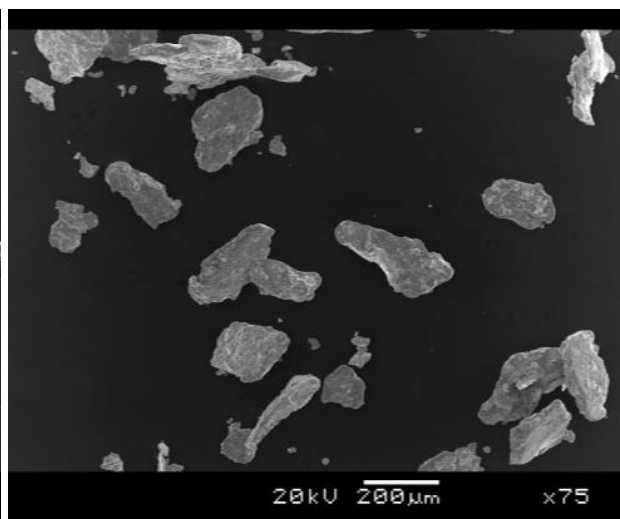

b)

Fig.3. a) Scarp of matrix material (ZA-27 alloy) used as carrier for nano-sized reinforcements [29] before high-energy ball milling, b) formed microparticles composite material after 3 hours of high-energy ball milling.

\section{Laser melting/sintering}

Additive manufacturing (AM) is a technology using a bottom-up approach of material synthesis where objects are obtained in a layer-by-layer manner. This method was originally used for rapid obtaining of prototypes and it was developed with time into manufacturing technology for obtaining fully functional parts of metals, nonmetals, and composites. AM enables obtaining of complex structures with precision and control not attainable with traditional manufacturing techniques [34]. The most common laser-based AM techniques used for obtaining metal components are selective laser sintering (SLS), and selective laser melting (SLM) [35]. In the SLS process melting of the powder is partial, while in the SLM technique starting material is fully melted.

SLS and SLM are methods for consolidation of powder materials layer by layer using a laser beam. This way, the 3D part of nearly final shape is obtained. SLS and SLM 
are characterized by extremely rapid processes of sintering or melting and solidification and has a large potential in the rapid production of metal components for different applications [36]. SLS is often followed by post-processing procedures, such as infiltration, coating, surface polishing, hot isostatic pressing (HIP) in order to improve the density, mechanical properties and surface quality of the components [37]. Another type of SLS is a green compact laser sintering (GCLS), i.e. laser sintering of cold-pressed compacts (compacts obtained by pressing of powder at room temperature). GCLS has a different mechanism compared to traditional powder metallurgy - generally, temperature generated on the surface of the compact by laser action is higher than in the conventional sintering and the time of reaction is relatively short, which can provide specific microstructure and PM components of high strength and density. SLM process has a similar mechanism as SLS, however the powder is completely melted and nearly fully dense parts are obtained. This eliminates the need for post processing procedures such as infiltration and heat treatment, usually necessary in SLS. SLM process is superior concerning quality, processing time and reliability.

In recent studies $[38,40,41]$, research is conducted in the important area of the development of high-performance contemporary materials by SLS and SLM. Possibilities for synthesis and characteristics of novel metal materials are investigated, including nanostructured materials, particle-reinforced metal-based composites, etc. Studies are multidisciplinary comprising laser technique, materials science, metallurgical and mechanical engineering. Various materials are examined and some of the results on copper-based alloys are presented here. The aim was to investigate dispersive and precipitation hardening of selected $\mathrm{Cu}$-materials through the new approach of selective laser melting and green compact laser sintering. Dispersoid particles were obtained by in situ reaction due to rapid solidification, while reinforcing precipitates were obtained by aging following the SLM or GCLS process. Physical processes during SLM are still a subject of research because of their nonequilibrium nature, and the obtaining of in situ formed reinforcements is even more complex. The application of SLM for synthesis of copper-based composite materials is known in literature with most of the studies employing continuous lasers with several $\mathrm{kW}$ power. Our work demonstrates the pulsedSLM/GCLS process for obtaining in situ reinforced copper alloys and its composites: $\mathrm{Cu}-$ $\mathrm{Ti}, \mathrm{Cu}-\mathrm{Ti}-\mathrm{TiB}_{2}$ and $\mathrm{Cu}-\mathrm{Zr}-\mathrm{ZrB}_{2}$ [38-41]. Pulsed lasers are becoming more interesting for SLM applications due to better control of the heat delivered to the material. Alloys are obtained in the form of foils through GCLS and 3D pieces through selective laser melting layer-by-layer. An innovative approach, contained of mechanical alloying and pulsedSLM processes, was used for manufacturing copper-based composites with the aim to improve their wear resistance [42]. The study reported that laser-sintered samples show better cavitation erosion resistance compared to samples obtained by powder metallurgy (densification did by hot pressing). Potential application of novel copper alloys and copper matrix composites is in electronic industry and nuclear techniques. Figures 4-6 show some of the copper-based samples obtained through SLS and SLM techniques. 


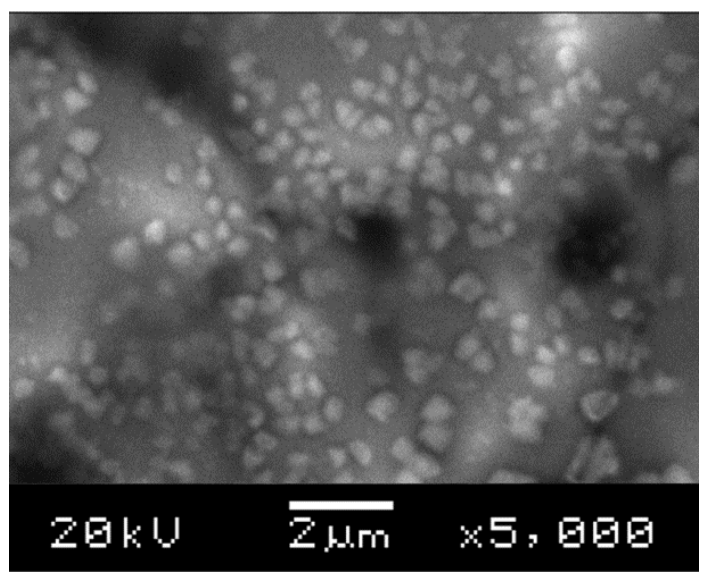

Fig. 4. SEM analysis. Characteristic microstructure of the GCLS sample (copper matrix) with prominent $\mathrm{ZrB}_{2}$ particles [40].

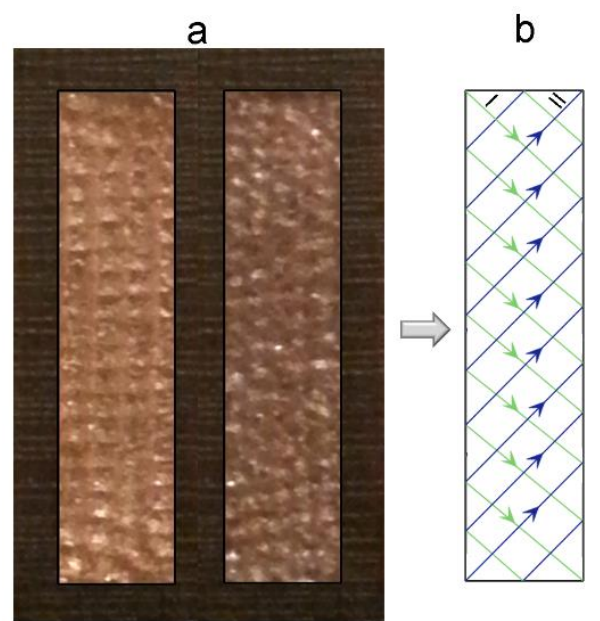

Fig. 5. a) Cu-Ti (left) and Cu-Ti-TiB 2 (right) alloy foils obtained by GCLS; b) scanning scheme [38].
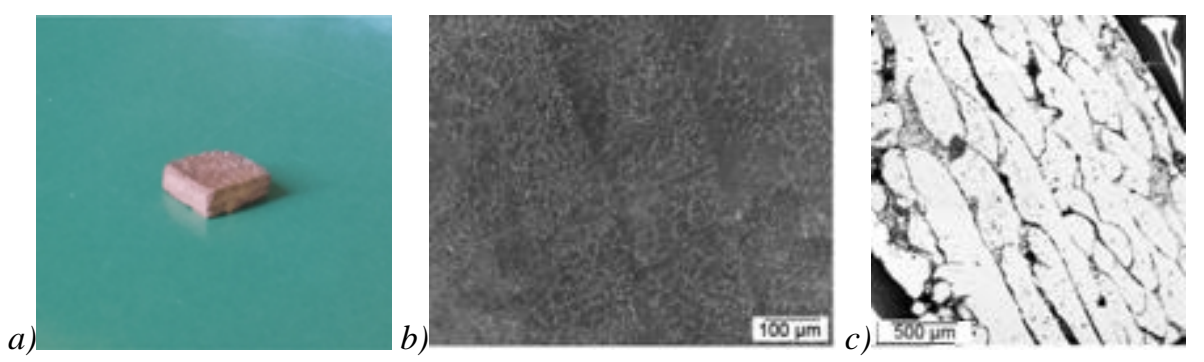

Fig. 6. Laser melted Cu-Ti-TiB 2 sample obtained by SLM: a) 3D compact; b) upper surface; c) cross-section [41]. 


\section{Summary}

The development of new materials is based on the comprehensive knowledge of the microstructural properties of each phase involved, as well as their distribution, mutual interactions, and bonding strength. On the other hand, technological progress is governed by continuous improvement of properties of existing material as well as the development of new materials with superior performances. Extensive use of composite materials in various industries is based on their ability to provide necessary properties and adapt to applications' specific needs. Metal matrix composites are widely used due to their advanced mechanical and physical properties such as high stiffness and strength, excellent conductivity, and wear and corrosion resistance. The main goal of MMCs design is to produce material with controlled microstructure and performances. Optimization of the processing parameters of MMCs attracts the great attention of engineers and researchers from many fields. Recent studies indicate that high-energy ball milling/mechanical alloying is a complementary technique with powder and ingot metallurgy, as well as with techniques in additive manufacturing providing an innovative processing route for MMCs manufacturing. Mechanical alloying is a mechanochemical process which enables a good distribution of reinforcements within the metal matrix, and adequate activation of powders for in situ formation of reinforcements using both, conventional and contemporary technologies.

\section{Acknowledgements}

The data regarding the simulation work presented here is supported through DeMoMet project which has received funding from the European Union's Horizon 2020 research and innovation programme under the Marie Sklodowska-Curie grant agreement No 797372. The work related to compocasting, powder metallurgy, and laser sintering is funded by the Ministry of Education, Science and Technological Development of the Republic of Serbia.

\section{References}

[1] S. M. Sapuan, Composite Materials-Concurrent Engineering Approach, Chapter 3- Composite Materials, first ed., Butterworth-Heinemann, Oxford, 57-93, 2017

[2] M. Haghshenas, Reference Module in Materials Science and Materials Engineering, Chapter Metal-Matrix Composites, 1-28, 2016.

[3] S. Zhang, Y. Ma, L. Suresh, A. Hao, M. Bick, S. C. Tan, J. Chen: ACS Nano, 14 (2020) 9282-9319.

[4] R. Bauri, D. Yadav, Metal Matrix Composites by Friction Stir Processing, Introduction to Metal Matrix Composites, first ed., 1-16, 2018.

[5] A.C. Cyrian, Metal Matrix Composites: History, Status, Factors and Future, first ed., Oklahoma State University, USA, 2011.

[6] T. W. Clyne, P. J. Withers, An Introduction to Metal Matrix Composites, Cambridge University Press, 1993.

[7] Y. Nishida, Introduction to Metal Matrix Composites: Fabrication and Recycling, Nagoya, Japan, 2013

[8] Jones, M.P. Gayer, E.E: The Journal of Historical Metallurgy Society, Vol. 23, pp.2.

[9] S. M. Sapuan, Polimer matrix composites, Penerbit University Putra Malaysia, Serdang, Selangor, 1999. 
[10] F. Salvemini, F. Grazzi, N. Kardjilov, I. Manke, A. Scherillo, M. G. Roselli, M. Zoppi: Eur. Phys. J. Plus, 135 (2020) pp.402 .

[11] T.W. Clyne, F.R. Jones, Metal matrix composites: matrices and processing, Elsevier Publications, 2006.

[12] Ruzic J., Stoimenov N., Advanced copper matrix composites, Academy Publishing House, Sofia, Bulgaria, 2016.

[13] N. Stoimenov, J. Ruzic: IFAC-PapersOnLine journal, 52 (25) (2019) pp.462.

[14] P. Balaz, Mechanochemistry in Nanoscience and Minerals Engineering, Berlin Heidelberg, Springer-Verlag, 2008.

[15] M. El-Eskandarany, Mechanical Alloying: Nanotechnology, Materials Science and Powder Metallurgy, second ed., Elsevier, Amsterdam, 2015.

[16] C. Suryanarayana: Prog. Mater. Sci. 46 (2001) 1-184.

[17] A. Gupta, , D. Yan, Mineral Processing Design and Operations: An introduction, second ed. Elsevier, 2006.

[18] O. D. Neikov, I. B. Murashova, N. A. Yefimov, S. Naboychenko, Handbook of Non-Ferrous Metal Powders: Technologies and Applications, first ed., Elsevier, Amsterdam, 2009.

[19] P. R. Soni, Mechanical alloying: fundamentals and applications, Cambridge International Science Pub, Cambridge, UK, 2000.

[20] M. S. El-Eskandarany, Mechanical alloying for fabrication of advanced engineering materials, Noyes Publications, New York, 2001..

[21] J. Ružić, J. Stašić, V. Rajković, K. Raić, D. Božić, Sci. Eng. Compos. Mater. 22 (6) (2015) p. 665.

[22] J. Ružić, J. Stašić, V. Rajković, D. Božić: Mater. Des. 62 (2014) p. 409.

[23] J.S. Andrus, R. G. Gordon, NASA Contractor Report, Florida, 1989.

[24] D. Božić, J. Stašić, B. Dimčić, M. Vilotijević, V. Rajković: Bull. Mater. Sci. 34 (2011) p.217.

[25] C. R. Deckard, Method and apparatus for producing parts by selective sintering, Patent number WO 1988002677 A2, 1988.

[26] C. Wang, H. Lin, Z. Zhang, W. Li: J. Alloys Compd. 748 (2018) p. 546.

[27] K. S. Raju, V. B. Prasad, G. B. Rudrakshi, S. N. Ojha: Powder Metall. 46 (3) (2003) p.219.

[28] I. Bobić, J. Ružić, B. Bobić, M. Babić, A. Vencl: Materials Mater. Sci. Eng. A 612 (2014) p.7.

[29] B. Bobic, A. Vencl, J. Ruzic, I. Bobic, Z. Damnjanovic, J. Compos. Mater. 53 (15) (2019) p.2033.

[30] A. Vencl, I. Bobic, B. Bobic, K. Jakimovska, P. Svoboda, M. Kandeva, Friction 7(4) (2019) p.340.

[31] A. Vencl, F. Vučetić, B. Bobić, J. Pitel, I. Bobić, Int. J. Adv. Manuf. Technol., 100 (9-12) (2019) p.2135.

[32] S. Veličković, B. Stojanović, M. Babić, I. Bobić, A. Vencl, G.V. Bognár, F. Vučetić: J. Braz. Soc. Mech. Sci. Eng. 41(1) (2019) p. 19.

[33] B. Stojanović, A. Vencl, I. Bobić, S. Miladinović, J. Skerlić: J. Braz. Soc. Mech. Sci. Eng., 40(6) (2018) p. 311.

[34] S.A.M. Tofail, E.P. Koumoulos, A. Bandyopadhyay, S. Bose, L. O’Donoghue, C. Charitidis, Mater. Today 21(1) (2018) p. 22.

[35] D. Gu, Laser Additive Manufacturing of High-Performance Materials, SpringerVerlag, Berlin Heidelberg, 2015. 
[36] J.P. Kruth, P. Mercelis, L. Froyen, M. Rombouts: Rapid Prototyp. J. 11(1) (2005) p. 26.

[37] J.P. Kruth, L. Froyen, J.V. Vaerenbergh, P. Mercelis, M. Rambouts, B. Lauwers: J. Mater. Process. Technol. 149 (1-3) (2004) p. 616.

[38] J. Stašić, D. Božić: J. Alloys Compd. 762 (2018) p. 231.

[39] J. Stašić, M. Trtica, V. Rajković, J. Ružić, D. Božić: Appl. Surf. Sci. 321 (2014) p. 353.

[40] J. Stašić, V. Rajković, J. Ružić, D. Božić: Int. J. Adv. Manuf. Technol. 80 (2015) p. 1049.

[41] J. Stašić, D. Božić: Int. J. Mater. Res. 111 (2020) p. 153.

[42] J. Ružić, J Stašić, D Božić, M Dojčinović, T Volkov-Husović: Metall. Mater. Eng. 23 (4), (2017) p. 291.

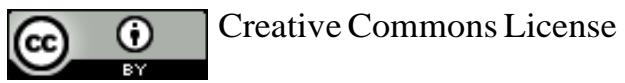

This work is licensed under a Creative Commons Attribution 4.0 International License. 